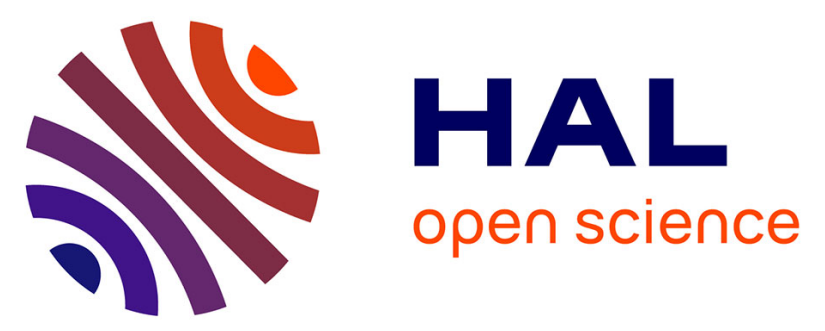

\title{
Preliminary Requirements and Architecture Definition for Integration of PLM and Business Intelligence Systems
}

Magali Bosch-Mauchand, Matthieu Bricogne, Benoît Eynard, Jean-Philippe

Gitto

\section{To cite this version:}

Magali Bosch-Mauchand, Matthieu Bricogne, Benoît Eynard, Jean-Philippe Gitto. Preliminary Requirements and Architecture Definition for Integration of PLM and Business Intelligence Systems. IFIP International Conference on Advances in Production Management Systems (APMS), Sep 2014, Ajaccio, France. pp.265-272, 10.1007/978-3-662-44739-0_33 . hal-01388259

\section{HAL Id: hal-01388259 \\ https://hal.inria.fr/hal-01388259}

Submitted on 26 Oct 2016

HAL is a multi-disciplinary open access archive for the deposit and dissemination of scientific research documents, whether they are published or not. The documents may come from teaching and research institutions in France or abroad, or from public or private research centers.
L'archive ouverte pluridisciplinaire HAL, est destinée au dépôt et à la diffusion de documents scientifiques de niveau recherche, publiés ou non, émanant des établissements d'enseignement et de recherche français ou étrangers, des laboratoires publics ou privés.

\section{(c)(1)}

Distributed under a Creative Commons Attribution| 4.0 International License 


\title{
Preliminary requirements and architecture definition for integration of PLM and Business Intelligence systems
}

\author{
Magali Bosch-Mauchand ${ }^{1}$, Matthieu Bricogne ${ }^{1}$, Benoît Eynard ${ }^{1}$, Jean-Philippe Gitto $^{1}$ \\ ${ }^{1}$ Université de Technologie de Compiègne, \\ Department of Mechanical Systems Engineering, \\ CNRS UMR7337 Roberval \\ CS 60319, 60203 Compiègne Cedex, France \\ \{magali.bosch, matthieu.bricogne, benoit.eynard, jean- \\ philippe.gitto\} dutc.fr
}

\begin{abstract}
With the advance of information systems and business intelligence technologies, new possibilities and functionalities to measure, monitor and control processes have emerged in the research area and in the market. In the context of PLM system, not only KPI for strategic goals can be measure and indicators for decision but also operational metrics link to product, project and process to manage agility of companies.
\end{abstract}

Keywords: PLM, Business Intelligence, Project Management, Performance Measurement, Agile methods.

\section{Introduction}

According to Gröger et al., "Agility is a critical success factor for manufacturers in volatile global environment and requires employees monitoring their performance and reacting quickly to turbulences." [1] An extrapolation can be drawn to the engineering processes, including engineering product and manufacturing process design, where actors and collaborators must have the means to monitor their performances, take decisions regarding them and react if required. This reaction can be necessitated to "respond to unpredicted changes like a late customer request, a designer failure, or some other external environmental impact" [2], but also to respond to poor performance detection. The performance measurement in engineering processes can be based on data shared by the Information System (IS) applications of Product Lifecycle Management (PLM). In fact, to be able to perform measurement on data, companies "will continue to face new and ever-increasing issues surrounding the quality of the data on which they rely", with companies incorporating data from a wider variety of sources [3]. In order to provide appropriated indicators for performance monitoring, in PLM system, the data integration is a crucial issue and it relies on various systems interoperability and their applications or data together [3]. A focus must be done on Business Intelligence (BI) systems enabling engineering process performance measurement and Integrated Decision System Support (IDSS).

adfa, p. 1, 2011 .

(C) Springer-Verlag Berlin Heidelberg 2011 
The paper proceeds as follows: the second section introduces a background in performance measurements (KPI - Key Performance Indicators and metrics), in BI as performance dashboard provider and in PLM as operational data sources. The third section is dedicated to PLM-BI systems requirements for performance management. Finally, the fourth section reports on a proposed architecture to manage data for operational decision making within PLM-BI application.

\section{Background}

\subsection{KPI and metrics for performance measurement}

In order to improve competitiveness, companies measure, monitor, and analyze their performance. Performance Management Systems (PMS) are regularly implemented as "balanced and dynamic solutions requiring considerable human and financial resources, and offering support to the decision-making process" [4]. According to Neely et al. [5], Performance Measurement can be defined as "the process of quantifying the efficiency and effectiveness of action"; a performance measure can be defined as "a metric used to quantify the efficiency and/or effectiveness of an action"; a PMS can be defined as "the set of metrics used to quantify both the efficiency and effectiveness of actions".

Key Performance Indicators are global metrics largely used in manufacturing industries to assess the efficiency and effectiveness of production workflow and the MES - Manufacturing Execution System [6; 7]. Based on this type of metrics, most PMSs are mainly historical and static. They are not dynamic and sensitive to changes in the global environment of the company. As a result, the information reflected by KPI is not relevant, up-to-date or accurate [8; 9]. In order to make PMS more efficient, KPI need to become dynamic and process dependent.

KPI and PMS design need to be based on companies' strategies and operational process $[10 ; 11]$. In the same consideration, various methodologies aiming to determine relevant KPI in engineering design processes have arisen in the last few years for instance in New Product Development [12] or engineering department management [13].

In this section, dynamic metrics and KPI concepts have been presented to support performance measurement. These indicators are actually mainly used in the manufacturing field, but great perspectives are envisioned in the product design and in the manufacturing process design. In the next section, emerging BI concepts are presented to assist decision making process.

\subsection{BI system as performance dashboards provider}

To monitor their performance, companies use specific performance dashboard derived from BI system. These BI systems are based on a set of models, methods, and tools that convert "raw" data into meaningful and useful information for business performance control. As defined by Negash [14], "BI systems combine data gathering, data storage, and knowledge management with analytical tools to present complex internal 
and competitive information to planners and decision makers." In BI technologies, three types of views of business activities can be provided: historical, current and predictive views. The most common functions of BI technologies are: reporting, On Line Analytical Processing (OLAP), analytics, data mining, process mining, complex event processing, business performance management, predictive analytics, and prescriptive analytics.

BI traditional components are data warehouse, data sources management, data marts, query and reporting tools. For instance, in the perimeter of supply chain management systems, information from various sources are collected and loaded through extract and transformation applications (ETL - Extract Transform Load) into the data warehouse [15].

According to Abdelfattah [16], the issue to select the right dashboard system architecture is to understand user requirements and the complexity of the metrics and applications that this dashboard needs to provide. It distinguishes seven dashboard architecture categories [16]: Direct Query; BI Tools; Mashboards; in-Memory Dashboards; Data Federation; Data Marts; Complex Event Processing (CEP). The competitive pressure of today's businesses has led to the increased need for near real-time BI. The goal of near real-time BI (also called operational BI or just-in-time BI) is to reduce the time latency between when operational data is acquired and when analysis over them is feasible, as CEP example in [17].

Dashboards are expected to "improve decision making by amplifying cognition and capitalizing on human perceptual capabilities" [18]. In this paper, the aim is to point out the expected benefits of the integration between design based dashboard and manufacturing based dashboards for decision support.

In this section, dynamic dashboard functionality of BI systems has been presented as a way to display appropriate indicators for performance measurement. In the next section, PLM systems, especially Product Data Management (PDM) and Manufacturing Process Management (MPM) functionalities are presented as interesting data sources for dashboard.

\subsection{PLM as operational data source}

PLM is defined as "a strategic business approach that applies a consistent set of business solutions in support of the collaborative creation, management, dissemination, and use of product definition information across the extended enterprise from concept to end of life" [19].

PLM aims at integrating the various processes and phases involved during a typical product lifecycle with collaboration in product development processes [20]. PLM system has to be consider, from a technical point of view, as a collaborative IS platform, not a single tool or package. It shares product data among actors, processes and organizations in the different phases of the product lifecycle for achieving desired performances and sustainability for the product/project/process [21].

In PLM systems, information mainly relies on product data, design logic, assembly, tolerance information, the evolution of products and product families [22]. PLM 
systems are fully integrated with enterprise IS and maps with processes and organization. It takes into account needs of project team members and product end-users.

In PDM and MPM modules, static and predefined reports presented as dashboards are provided as standard functionality to follow change management and manufacturing process management. Some systems or complementary modules allow defining specific reports but few use the possibility of BI systems. A list of Product Development Metrics is given by Kenneth Crow from DRM Associates [23]. Some researches aim at defining KPI for PLM implementation and monitoring [24] and even if the objective is not the same, some of these KPI seems to be adapted to PLM system inuse monitoring. In most of PLM system, the statistical metrics are no up-to-date information, measured at regular times and stored for historical purpose. Two kinds of statistical metrics links to business report can be identified. The first one falls relates on data characteristics such as number, quantity and types of objects or documents (files, Engineering Change Request, Engineering Change Order, Computer Aided Design documents...). The second one related on the usage of each PDM/MPM functionality (query, create report, standard parts usage, parts reuse...).

There exists also a real need for monitoring metrics that are up-to-date information used for management and maintenance of the PLM system by IT Department. These monitoring metrics, such as IS supervision (Central Processing Unit (CPU), alive processes, disk space, bandwidth...) and system exploitation (connections number, number of opened sessions, license activation).

Other types of metrics can be useful in PLM system such as « Collaboration performance » metrics or Quality Assurance for Software setting metrics based on bug tracker tools [25] As an extension to [26], all engineering processes face the same challenges: dealing with technical complexity of product and process; understanding the interactions and dependencies between phases and partials model; and, evaluating the status of a product/project/process.

\section{PLM-BI system requirements for performance management and architecture definition}

In the previous section, a focus was done on the operational data available in PLM system that are not relevantly use to monitor and control product/project/process: PLM systems are great IT support to capture data on products and engineering processes that have to be exploited to provide metrics/indicators of performance.

\subsection{PLM-BI system current researches}

Numerous researches point out how BI framework could be used in the context of PLM in order to refine information for better decision making [27]. Depending on the maturity level of PLM system, the use of BI in PLM environment can be considered as premature. Maturity models can be characterized as special types of roadmaps for implementing practices in an organization, and their purpose is to help in the continuous improvement of the capabilities of an organization in certain application or management areas [28]. 
Liu at al. point out that "a limitation of current BI-concepts is the neglecting of engineering data and technical process attributes" [29]. Relevant and accurate data and information integration is the most fundamental issue for all integration aspects in IDSS and this integration is crucial for the construction of relevant analysis based on estimated indicators because data is the basic format for decision variables, constraints and objective functions [30].

In [31], Do focuses on PDM system and the monitoring of ongoing product development process based on KPI regarding quality, cost and delivery metrics for product and design activities. He proposes a specific Product Data Model and a specific Multidimensional Product Data Model to structure the data in the BI system used for predefined metrics. But this type of architecture does not insure flexibility for the KPI dashboard management; the structure and metrics model is predefined and thus static.

The dashboards integrated within PLM systems that provide current and historical product and process data, allow comprehensive, reliable monitoring and control of product/project/process [6]. Also, in [6], authors highlight the needs for indicators management solutions, integrated within a PLM system, to manage three main areas: Design for $\mathrm{X}$ (product-oriented indicators such as cost, weight, space requirement, energy consumption, assembly etc.), project controlling (time or cost efficiency indicators) and PLM performance improvement ("Process Indicators for Product Engineering“").

\subsection{PLM-BI system needs, uses and requirements}

The companies have understood the importance of metrics-driven management to estimate the goals defined by their strategy [15]. As for manufacturing process, the proposed levels of dashboards are modelled on company's organization levels [1]. Three types of dashboard must be set: strategic/enterprise control, tactical/project control and operational/process dashboards. In the tactical/project control dashboard, monitoring for IS expert and Product Development manager has to be set. At each level, specific dynamical metrics have to be measured.

A survey and synthesis paper on the current research efforts with regard to the development of IDSS was written by Liu et al. [30]. This paper underlines that such system must be compatible with new BI systems and allows more flexibility and agility. The process improvement is not limited to the efficiency and effectiveness of the decisions, but has to integrate collaborative support and virtual team working improvement. Such a system must be characterized by its responsiveness and its agility [9]. The responsiveness of a PLM-BI system is its ability to provide real time reports on PLM processes. The agility of a PLM-BI system is defined by its ability to adapt itself to changes or organizational modifications.

\subsection{Proposal for data extraction, transformation and loading : the workers}

For each of involved components of IS, the goal is to extract the required data and to store it in the Data Repository (DR). This functionality is performed by a specific machine, called in this paper a worker (Fig. 1) [34]. 


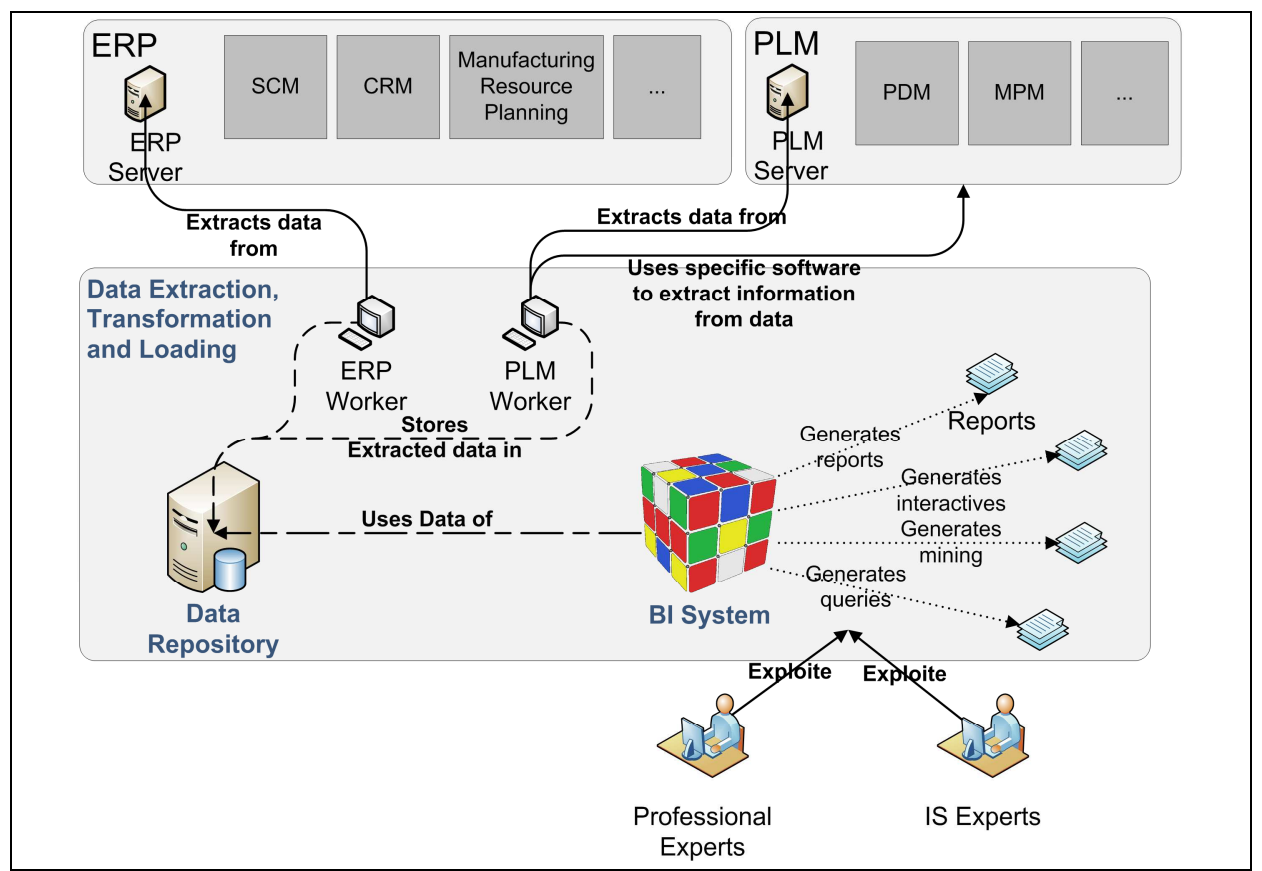

Fig. 1. PLM metrics extraction and storage for performance measurement thanks to BI system

Each worker is dedicated to a specific IS: it takes advantage of the extension's capabilities of every component in terms of chosen programming language, available Application Programming Interface (API), data model, etc...[33]

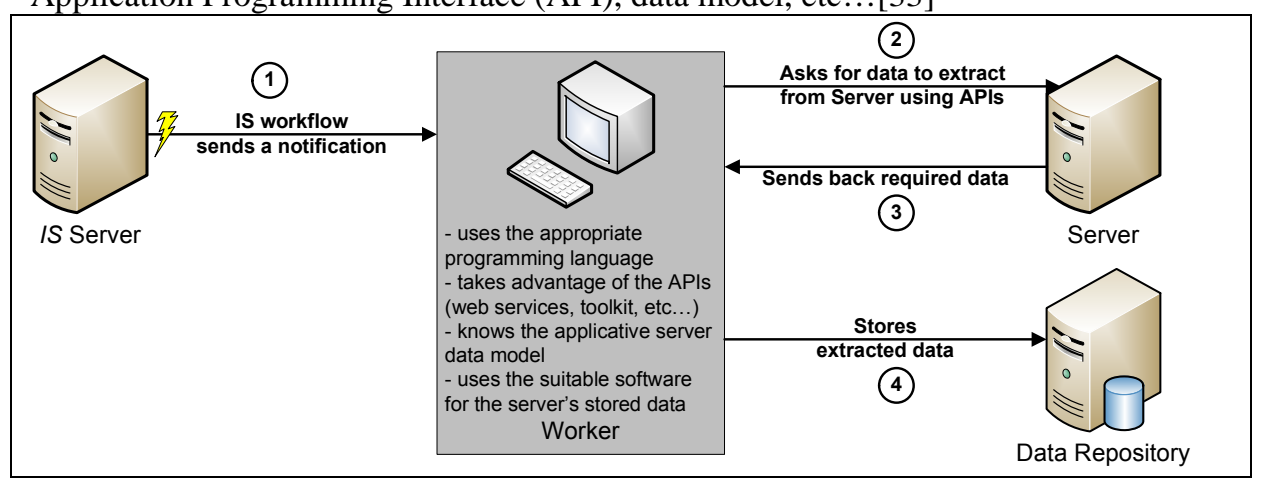

Fig. 2. Workers' processes for data extraction

Sometimes, the data stored in the IS component need to be managed by specific application. In this case, this application can be installed in the worker system in order to extract the desired information and to store it in the DR. For instance, in a PDM system, CAD data can be retrieved, opened and analyzed in order to store the proper information (e.g. the mass of the product) in the DR (Fig. 2). 


\section{Conclusion}

In this paper, the issue of enhancing PLM systems monitoring by performance control by applying BI concepts has been introduced. Needs of specific and relevant metrics for engineering process and PLM IS monitoring has been highlighted. Future work aims at defining a case study aiming to monitor product quality factor based on PLMBI system.

\section{Acknowledgements}

This work was carried out in the framework of the LabCom DIMEXP, funded by the French Government, through the program "Investments for the future" managed by the National Agency for Research (Reference ANR-13-LAB1-0006-01).

\section{References}

1. Gröger, C., Hillmann, M., Hahn, F., Mitschang, B., \& Westkämper, E., The Operational Process Dashboard for Manufacturing. Procedia CIRP, 7, 205-210 (2013).

2. Bricogne, M., Troussier, N., Rivest, L .\& Eynard, B. Agile design methods for mechatronics system integration. In: Bernard, A., Rivest, L., and Dutta, D. (eds.) IFIP WG 5.1 International Conference, PLM 2013. pp. 458-470., Nantes, France (2013).

3. Isık O., Jones, M. C. \& Sidorova, A. Business intelligence success: The roles of BI capabilities and decision environments. Inf. \& Manag., 50, 13-23 (2013).

4. Vukšić, V. B.; Bach, M. P. \& Popovič, A. Supporting performance management with business process management and business intelligence: A case analysis of integration and orchestration. Int. J. of Inf. Manag., 33, 613-619 (2013).

5. Neely, A., Gregory, M. \& Platts, K. Performance measurement system design: A literature review and research agenda. Int. J. Oper. Prod. Manag. 25, 1228-1263, (2005).

6. Kickstein, J. \& Drewinski, R. Systematic indicator management as a component of a PLM environment Controlled product and process, Product Data Journal, 28-31 (2012).

7. Kemper, H., Baars, H. \& Lasi, H. Kemper, H.-G.; Baars, H. \& Lasi, H. An Integrated Business Intelligence Framework, Business Intelligence and Performance Management, Rausch, P.; Sheta, A. F. \& Ayesh, A. (Eds.), Springer London, 13-27 (2013).

8. Đurić, Ž., Maksimović, R., Efficiency of applying a model for measuring key performance indicators in an industrial enterprise, Sc. Research and Essays, 8(14), 554-574 (2013).

9. Nudurupati, S. S., Bititci, U. S., Kumar, V. \& Chan, F. T. S. State of the art literature review on performance measurement. Comput. Ind. Eng. 60, 279-290 (2011).

10. Lohman, C.; Fortuin, L. \& Wouters, M., Designing a performance measurement system: A case study, European Journal of Operational Research, 156, 267-286 (2004).

11. Neely, A. Gregory M., Platts K., Performance measurement system design: developing and testing a process-based approach. Int. J. Oper. Prod. Manag. 20, 1119-1145, (2000).

12. Cheng, Y.-T.; Chou, H.-H. \& Cheng, C.-H. Extracting key performance indicators (KPIs) new product development using mind map and Decision-Making Trial and Evaluation Laboratory (DEMATEL) methods, African J. of Business Manag., 5, 10734-10746 (2011). 
13. Beisheim N., Stotz F., Key Performance Indicators for Design and Engineering, Concurrent Engineering Approaches for Sustainable Product Development in a MultiDisciplinary Environment, pp 341-351 (2013).

14. Negash, S.: Business Intelligence, in Communications of the Association for Information Systems, 13, 77 (2004).

15. Sahay, B. \& Ranjan, J., Real time business intelligence in supply chain analytics, Information Management \& Computer Security, 16, 28-4 (2008).

16. Abdelfattah, M.: A Comparison of Several Performance Dashboards Architectures, Journal of Intelligent Information Management, 05, 35-41 (2013).

17. Chaudhuri, S.; Dayal, U. \& Narasayya, V. D'Atri, A., An overview of business intelligence technology, Communications of the ACM, ACM, 54, 88 (2011).

18. Yigitbasioglu, O. M. \& Velcu, O. A review of dashboards in performance management: Implications for design and research. Int. J. of Accounting Inf. System, 13, 41-59 (2012).

19. CIMdata, Product Lifecycle Management - Empowering the Future of Business, CIMdata Inc, USA, (2003).

20. Sharma A., Collaborative product innovation: integrating elements of CPI via PLM framework, Comput.-Aided Des., 37 (13), 1425-1434, (2005).

21. Terzi S., Bouras A., Dutta D., Garetti M., Kiritsis D. Product lifecycle management - from its history to its new role', Int. J. of Product Lifecycle Manag., 4( 4), 360-389, (2010).

22. Rachuri S., Fenves S.J., Sriram R.D., Wang F., A product information modeling framework for product lifecycle management, Comput.-Aided Des., 37 (13), 1399-1411, (2005).

23. Product Development Metrics, http://www.npd-solutions.com/metrics.html

24. Alemanni, M., Alessia, G., Tornincasa, S., \& Vezzetti, E., Key performance indicators for PLM benefits evaluation: The Alcatel Alenia Space case study. Comput. in Ind., 59(8), 833-841 (2008).

25. Kenny, E. \& Meneses, D. Common Framework for Extracting Information and Metrics from Multiple Change Trackers, EGI Community Forum 2012 / EMI Second Technical Conference, (2012).

26. Hahn, A.; Austing, S. G. \& Strickmann, J., Metrics - The business intelligence side of PLM, Int. Conf. on Product Lifecycle Management 2007, PLM'07, 11-20 (2007).

27. Jussi Myllärniemi, Jussi Okkonen, H. K., Utilizing Business Intelligence Framework for Leveraging Product Lifecycle Management, the 9th Int. Conf. on Elect. Business, (2009).

28. Kärkkäinen H., Myllärniemi J., Okkonen J., Silventoinen A., Assessing Maturity Requirements for Implementing and using Product Lifecycle Management, the 9th Int. Conf. on Elect. Business (2009).

29. Koch, M., Baars, H., Lasi, H., Kemper, H.-G., Manufacturing Execution Systems and Business Intelligence for Production Environments, in Proc. of the 16th AMCIS, (2010).

30. Liu, S.; Duffy, A. H. B.; Whitfield, R. I. \& Boyle, I. M., Integration of decision support systems to improve decision support performance, Knowledge and Information Systems, 22, 261-286 (2009).

31. Do, N., Application of OLAP to a PDM database for interactive performance evaluation of in-progress product development. Comput. in Ind., 1-10 (2014).

32. Lasi, H.: Industrial Intelligence - A Business Intelligence-based Approach to Enhance Manufacturing Engineering in Industrial Companies, Procedia CIRP, 12, 384-389 (2013).

33. Kickstein, J. \& Drewinski, R. Systematic indicator management as a component of a PLM environment Controlled product and process, Product Data Journal, 28-31 (2012).

34. Bricogne M., Belkadi F., Bosch-Mauchand M., Eynard B., Knowledge based Product and Process Engineering enabling Design and Manufacturing Integration, In: Advances in Production Management Systems. New Challenges, New Approaches. pp. $473-480$ (2010). 